\title{
CUSTEIO BASEADO EM ATIVIDADES \\ (ABC) APLICADO AOS PROCESSOS DE COMPRA E VENDA DE DISTRIBUIDORA DE MERCADORIAS
}

\section{RODNEY WERNKE}

Prof. Dr. do Curso de Administração da Universidade do Sul de Santa Catarina - SC

E-mail: rodneyw@unisul.br

\section{RESUMO}

Trata-se de estudo de caso sobre a aplicação do Custeio Baseado em Atividades (ABC) efetuada em empresa que atua na distribuição de mercadorias. $O$ estudo teve por objetivo identificar o efetivo consumo de recursos destinados aos processos de compra e de venda pelos três principais segmentos de mercado em que a entidade atua, no sentido de melhorar sua análise de rentabilidade. Após efetuar uma revisão da literatura sobre os principais aspectos do ABC, descreve-se o estudo efetuado. Inicialmente, faz-se a caracterização da empresa em que foi efetuada a pesquisa. Em seguida, apresentam-se os detalhes da implementação do ABC, comentando os procedimentos realizados para tal finalidade. Por último, são mencionadas as informações gerenciais mais relevantes que puderam ser obtidas pelo uso dessa forma de custeio.

Palavras-chave: Estudo de Caso, ABC, Distribuidora de Mercadorias.

\begin{abstract}
This case study discussed the application of activity-based costing (ABC) in a merchandise distribution company and aimed to identify the effective consumption of purchase and sales process resources by the three main market segments the entity is active in, so as to improve its profitability analysis. After a literature review on the main aspects of $A B C$, the case study was described. First, the study company was characterized. Next, the details of $A B C$ implementation were presented, including what procedures were realized for this purpose. Finally, the most relevant management information obtained through this costing method were mentioned.
\end{abstract}

Keywords: Case Study; ABC; Merchandise Distributor. 


\section{PROLEGÔMENOS}

Fatores como abertura de mercados e acirramento da concorrência conduzem os empresários e gestores das organizações a procurarem métodos que auxiliem na tomada de decisões, essenciais à sua permanência no segmento de mercado em que estão inclusas. Com isso, a Contabilidade Gerencial passa a ganhar mais importância em razão de que pode facultar o acesso a informações consistentes que auxiliam os administradores na condução lucrativa de seus negócios num ambiente de alta competitividade.

Nessa direção, um dos aspectos fundamentais a serem examinados pelos administradores são os gastos efetuados para manter as operações em andamento e fornecer seus produtos aos clientes (normalmente considerados como despesas administrativas, comerciais ou financeiras). Nesse ponto, surge o problema da definição da forma a ser empregada para alocar tais gastos aos produtos ou serviços. Essas despesas, atualmente, podem representar uma fatia substancial do total de recursos despendidos pelas empresas de diversos setores e vêm crescendo com o passar dos anos, merecendo maior atenção dos gestores.

Para minimizar esse problema, dentre outras possibilidades existentes na literatura pertinente, tem sido utilizado o Custeio Baseado em Atividades (ABC - Activity-Based Costing). Tal ferramenta aprimorou a gestão financeira à medida que permitiu identificar os gastos com atividades associadas aos processos executados na empresa, verificando de que forma essas atividades se relacionam com a geração de receitas e qual o respectivo consumo de recursos de sua parte. Por outro lado, para empresas não-industriais, em especial para organizações empresariais que atuam como distribuidoras de mercadorias, a literatura nacional não é pródiga em textos que possam embasar aplicações de tal metodologia de custeio na gestão dessas entidades. Em razão disso, neste artigo se relata um estudo de caso relacionado com a utilização do Custeio Baseado em Atividades (ABC) numa distribuidora de mercadorias. Tal método foi implementado com o objetivo de proporcionar aos gestores informações a respeito da rentabilidade das principais linhas de comercialização, apurando quanto cada uma delas consome de recursos mensalmente, no que tange aos processos de compra e venda.

Para tanto, inicialmente se faz uma revisão da literatura acerca dos conceitos relacionados ao $A B C$ e citam-se as vantagens e limitações atribuídas a esse método de custeio. Em seguida, passa-se a descrever o estudo de caso realizado, evidenciando as características principais do contexto empresarial em lume, apresentam-se etapas seguidas para implementação e relatam-se os resultados alcançados. Por último são mencionadas as conclusões do estudo realizado.

\section{PRINCIPAIS ASPECTOS DO CUSTEIO BASEADO EM ATIVIDADES (ABC)}

Em relação ao surgimento do $A B C$, Kaplan e Cooper (1998, p. 15) asseveram que os sistemas de custeio baseados em atividades apareceram na década de oitenta, tendo por objetivo suprir a necessidade de informações mais precisas sobre o custo de cada atividade envolvida nos processos produtivos e na geração de serviços.

Contudo, tal assertiva é contestada por alguns autores. Nesse sentido, Nakagawa (1995, p. 41) comenta que há registros literários que noticiam a utilização do ABC por contadores em 1800 e no início de 1900, bem como do seu uso na década de 60 . Enfatiza que, no Brasil, os estudos e pesquisas sobre o ABC tiveram início em 1989, no Departamento de Contabilidade e Atuária da Faculdade de Economia, Administração e Contabilidade da Universidade de São Paulo (USP).

Já para De Rocchi (1994, p. 10), a origem do $A B C$ pode ser atribuída a Alexander $\mathrm{H}$. Church, que, já nos primeiros anos do século $\mathrm{XX}$, desenvolvia trabalhos baseados nessa concepção. Argumenta, também, que importantes contribuições a essa teoria podem ser consideradas as obras de Mellerowicz (publicada na década de 50 e denominada Platzkosten), Staubus (intitulada Activity costing and input-output accounting, datada de 1971) e Miller e Vollmann (Transaction based costing, do ano de 1985).

Mesmo com a divergência quanto ao aparecimento do custeio baseado em atividades, o mais importante são os benefícios propiciados pela utilização do $A B C$ na gestão dos custos das empresas. Para isso, cabe que sejam conhecidos os seus principais aspectos, conforme enfatizado a seguir.

$\mathrm{O}$ custeio baseado em atividades, para Warren et al. (2003, p. 394), emprega "os custos das atividades para determinar os custos do produto. Sob esse método, os custos indiretos de fabricação são inicialmente contabilizados em grupos de custos de atividades". Cada um desses grupos relaciona-se com uma atividade específica, como o uso de máquinas, inspeções, movimentações de setup e atividades de engenharia.

Young e O'Byrne (2003, p. 100) apregoam que o custeio baseado em atividades ajuda as compa- 
nhias a examinarem, mais racionalmente, as forças que conduzem o consumo de recursos nas operações. Aduzem que o ABC considera que a relação de causa e efeito entre as atividades executadas na empresa e os custos indiretos "é mais bem refletida por bases de alocação não relacionadas a volume, conhecidas como direcionadores de custos. Ao aplicar esse conceito, os administradores ganham um entendimento melhor das forças que conduzem os custos indiretos em suas divisões".

Shank e Govindarajan (1997, p. 221) defendem que o intuito principal do $A B C$ é a atribuição de uma parcela das despesas gerais (ou custos indiretos) aos produtos, com base na proporção de cada atividade que causem. Essa abordagem, segundo tais autores, "rejeita a noção de que toda a alocação de custos indiretos é arbitrária e assim não vale a pena tentar melhorá-la. A abordagem admite que uma significativa alocação de custos fixos é possível e que vale a pena ser feita".

Nakagawa (1995, p. 39) cita que "os recursos de uma empresa são consumidos por suas atividades e não pelos produtos que ela fabrica". $O$ objetivo do método de custeio $A B C$ é rastrear as atividades mais relevantes da organização, identificando rotas de consumo dos recursos e, através dessa análise, planejar o uso eficiente e eficaz dos recursos utilizados pela empresa, otimizando seus resultados.

Para a compreensão escorreita acerca do Custeio Baseado em Atividades é necessário dominar os conceitos enfocados nas próximas seções.

\subsection{Conceitos Inerentes ao Custeio Baseado em Atividades}

Para melhor entendimento da metodologia utilizada pelo sistema $\mathrm{ABC}$, faz-se necessário o conhecimento dos conceitos de "processos", "atividades", "tarefas" e "direcionadores de custos".

Processo, para Nakagawa (1995, p. 44), pode ser entendido como "uma cadeia de atividades relacionadas entre si, interdependentes e ligadas pelos produtos que elas intercambiam". Como exemplo de processo menciona o "Processo de Compras", que abrange as atividades de previsão de vendas, planejamento de material, controle de inventário, recebimento, inspeção, sistema de informação gerencial e contas a pagar, ou seja, o processo inicia na tomada de decisão da compra e termina quando a fatura for paga ao fornecedor.

Boisvert (1999, p. 93) cita que processos podem ser considerados como "o conjunto de atividades que têm um direcionador comum e um objetivo bem preciso, que possa ser identificado como cliente externo ou interno". Como exemplos de processos, esse autor cita: responder à reclamação do cliente, realizar análise de pedido de crédito, verificar os balanços financeiros, montar um produto etc.

Atividades, de acordo com Kaplan e Cooper (1998), são descritas por verbos e seus objetos associados: programar produção, transferir materiais, comprar materiais, inspecionar itens, responder aos clientes, melhorar produtos, lançar novos produtos etc. Referidos autores (p. 107) enfatizam, também, que "as atividades são unidades básicas de acúmulo de custos nos sistemas ABC". Essas, também, podem ser agregadas para que os gerentes possam identificar o custo total de execução de um processo de negócios. Nesse caso, cada atividade pode ser codificada, permitindo que os custos sejam acumulados e informados por processos de negócios.

Santos (2001, p. 178) argúi que atividades "são as tarefas necessárias à realização de um processo e que consomem recursos da organização". Cita como exemplo, no caso do "processo de venda de uma viagem de turismo: divulgação do serviço, recepção ao cliente, comunicação com a operadora, emissão dos documentos de reserva, emissão dos documentos de cobrança etc".

As atividades, conforme Brimson (1996, p. 63), são "processos que consomem recursos substanciais para gerar uma produção", descrevendo o modo como uma empresa utiliza seu tempo e recursos para alcançar os seus objetivos. O referido autor considera que a função primordial de uma atividade é converter os recursos que a entidade dispõe (como matérias-primas, mão-de-obra e tecnologia) em produtos ou serviços.

Num nível de detalhamento maior, as atividades podem ser desdobradas em tarefas, que Brimson (1996, p. 63) define como sendo a combinação dos elementos de trabalho ou operações que compõem uma atividade, ou seja, tarefa é a forma de realização da atividade. Relata, ainda, que duas empresas podem executar uma mesma atividade empregando tarefas diferentes.

Para evidenciar a diferença entre atividades e tarefas, Boisvert (1999, p. 58) diz que a atividade reúne todas as tarefas realizadas seqüencialmente. llustra esse raciocínio com a ida ao Banco para sacar dinheiro de um caixa automático, quando é necessário efetuar tarefas como inserir o cartão magnético e digitar a senha, ou seja, "essas tarefas fazem parte da atividade que consiste em retirar dinheiro de um caixa automático. A tarefa é o elemento mais simples da atividade; normalmente, ela não se decompõe em outros elementos". 
Tão importante como a definição das atividades que compõem o processo produtivo é determinar como direcionar o custo dessas atividades para os produtos e/ou serviços gerados. Na concepção do $A B C$, para essa finalidade são utilizados os direcionadores de custos, que Martins (2003, p. 96) define como "o fator que determina o custo de uma atividade. Como as atividades exigem recursos para serem realizadas, deduz-se que o direcionador é a verdadeira causa dos seus custos", ou seja, no caso do custeio de produtos, o direcionador é o fator que determina ou influencia a maneira como os produtos vão "consumir" ou "utilizar" as atividades, constituindo-se na base utilizada para atribuir os custos das atividades aos produtos.

Atkinson et al. (2000, p. 308) entendem que o custeio baseado em atividades é um método que se apóia na idéia de que os direcionadores de custos podem vincular, diretamente, as atividades executadas aos produtos fabricados. Para esses autores os "direcionadores de custos medem o consumo médio ocorrido, em cada atividade, pelos vários produtos. Então, os custos das atividades são atribuídos aos produtos, na proporção do consumo que os produtos exerceram, em média, sobre as atividades".

Para Shank e Govindarajan (1997) o custo é causado, ou direcionado, por muitos fatores que se inter-relacionam de formas complexas. Compreender o comportamento dos custos significa compreender a complexa interação do conjunto de direcionadores de custo em ação em uma determinada situação.

No entender de Sakurai (1997, p. 100), direcionador de custos é "qualquer fator que cause uma alteração de custo de uma atividade". Tal autor assevera que o termo é empregado em duas situações: quando se deseja apropriar os recursos às atividades (nesse caso conhecido como "direcionador de recursos") e quando envolve o mecanismo contábil de imputação dos custos das atividades a objetos de custo, no sistema de Contabilidade (chamado, então, de "direcionador da atividade").

Kaplan e Cooper (1998) citam que os direcionadores utilizados no $A B C$ podem ser classificados em três tipos: (i) direcionadores de transação: que se referem ao número de operações repetitivas, como o número de setups, número de pedidos, número de veículos descarregados etc.; (ii) direcionadores de duração: que se relacionam com o tempo de execução de uma atividade e são empregados quando há grandes variações no tempo de realização de uma atividade, em função do produto ou serviço e (iii) direcionadores de intensidade: que consideram diretamente a quantidade de recursos necessária para realizar a atividade, sendo utilizados principalmente quando a realização da atividade for muito complexa ou específica.

Com relação à quantidade de direcionadores de custos, Nakagawa (1995, p. 74) destaca que variam de acordo com os seguintes fatores:

a) objetivos (pricing, redução de custos, avaliação de desempenho, investimentos, meIhoria de qualidade, flexibilidade, lead time etc.) e acurácia da mensuração que se deseja obter através do $A B C$ que está sendo desenhado;

b) participação relativa (\%) dos custos indiretos das atividades agregadas analisadas sobre o custo de conversão, em termos de número de itens (contas) e de seus valores;

c) complexidade operacional da empresa, em termos de produtos (diversidade de volumes, materiais utilizados, tamanhos, mix, número de partes/componentes, tecnologias etc.) e de clientes (diversidade de clientes/mercados atendidos, número de itens vendidos, sistemas/canais de distribuição etc.);

d) disponibilidade de recursos da empresa (financeiros, humanos, sistemas de coleta e processamento de dados, tempo, cultura etc.).

Após evidenciados os principais conceitos relacionados ao Custeio Baseado em Atividades $(A B C)$, cabe que sejam enfocadas as vantagens e limitações associadas a esse método de custeio, conforme consta da próxima seção.

\subsection{Vantagens e Limitações Atribuídas ao ABC}

Entre as vantagens do $\mathrm{ABC}$, conforme Cogan (1994), está a melhoria nas decisões gerenciais, devido à transparência permitida por esse método. $\mathrm{O}$ $\mathrm{ABC}$ permite a definição de ações para o melhoramento contínuo das tarefas de redução dos custos de overhead, diferentemente do sistema tradicional de custeio que concentrava os esforços para redução de custos nos custos diretos, ocultando os desperdícios existentes nas despesas indiretas.

Segundo Martins (2003), uma das grandes vantagens do $A B C$ é a de não restringir a análise ao custo do produto e sua lucratividade. A análise do $A B C$ permite que os processos ocorridos na empresa sejam custeados, pois são compostos por atividades que se inter-relacionam. Com isso, possibilita a visualização das atividades que podem ser 
melhoradas, reestruturadas ou, até mesmo, eliminadas dentro de um processo, de forma a melhorar o desempenho competitivo da empresa.

Contudo, como qualquer metodologia gerencial, o método $A B C$, também, possui algumas limitações ou restrições. Leone (2000) observa que o critério $A B C$ utiliza a metodologia do custeio por absorção, carregando com esse todas as suas limitações. Para o autor, a aplicação do critério ABC na análise dos custos e despesas indiretos atribui todos os itens indiretos para os estoques dos produtos, o que nem sempre é interessante. Outra desvantagem apresentada por Leone (op. cit.) diz respeito à aparente transformação de custos fixos em custos variáveis, isto é, quando os custos e as despesas são apropriados às atividades, o critério parece não se interessar pela dicotomia dos custos e das despesas em fixas e variáveis, simplesmente apropriando esses custos e despesas aos produtos ou serviços através dos direcionadores. Todos os custos e despesas serão considerados variáveis diante da unidade de medida que define o direcionador de custos. Assim, o critério ABC apuraria custos unitários excessivamente altos em um período de produção abaixo da capacidade normal da empresa.

Por sua vez, Catelli e Guerreiro (1994, p. 324) apontam como limitações inerentes ao ABC os seguintes pontos:

- o sistema $A B C$ não muda a realidade dos fatos, de que a grande parcela dos custos indiretos, qualquer que seja o tipo de atividade, é de natureza fixa;

- todo relacionamento de custos fixos das atividades com as unidades individuais de produtos por meio dos cost drivers está sujeito a fortes doses de subjetividade, assim como ratear esses custos proporcionalmente à mão-de-obra direta (não existe o critério objetivo isento de discussões);

- todas as atividades apresentam diferentes níveis de volume, portanto teremos no sistema $A B C$ diferentes custos unitários por atividade com os diferentes níveis de volume;

- tendo em vista que o emprego de tecnologias modernas de produção têm aumentado os custos fixos proporcionalmente aos custos variáveis, esse método de custeio conduzirá a resultados proporcionalmente mais errados;

- o uso do $A B C$ faz com que se transformem custos fixos em custos variáveis. Ou seja, sempre que se apura o custo fixo unitário é modificada a verdadeira natureza comportamental do elemento de custo, gerando informações distorcidas;

- o processo de rateio de custos fixos gera informações que impossibilitam a comparabilidade entre os custos de empresas concorrentes;

- o sistema $A B C$ não aborda conceitos avançados de mensuração, tais como valor econômico, custos de oportunidade, equivalência de capitais, custos correntes de reposição, entre outros. Assim, além da natural distorção dos custos causada pelos critérios de rateios, os objetos de custeio são medidos de uma forma que não expressa os seus valores econômicos.

\section{Cogan (1994, p. 7) acentua que o}

$A B C$, em sua forma mais detalhada pode não ser aplicável na prática, em virtude de exigir um número excessivo de informações gerenciais que podem inviabilizar sua aplicação. O custo da coleta e manipulação detalhada teria que justificar seu benefício. Numa fábrica, pode-se detectar mais de cem atividades que contribuem para o "overhead" - caso se pense numa apuração exata de todas essas atividades, o ABC seria impraticável.

Percebe-se, então, que na literatura há posicionamentos favoráveis e contrários à utilização do ABC. Contudo, em razão das necessidades informativas da empresa pesquisada, considerou-se que tal método seria o mais adequado ao contexto abrangido, motivando a aplicação do ABC, conforme descrito nos próximos tópicos de forma detalhada.

\section{ESTUDO DE CASO}

O estudo de caso foi realizado no primeiro semestre de 2004 na empresa "Braçonortense" (nome fictício por solicitação dos administradores), que atua na distribuição de mercadorias como medicamentos e perfumarias. Localizada em cidade do litoral sul de Santa Catarina, essa organização atende, principalmente, a uma clientela composta por farmácias, hospitais (públicos e privados), supermercados e mercearias situados na região sul do Brasil.

A aplicação do ABC ora relatada abrangeu, especificamente, o Centro Administrativo da empresa, onde são realizadas as atividades ligadas aos processos de compra e venda da entidade. A empresa 
conta, ainda, com um Centro de Distribuição, localizado em outro bairro do mesmo Município, onde são armazenadas, fracionadas e preparadas mercadorias para remessa aos clientes, não abrangido por este estudo.

O objetivo principal da utilização do custeio baseado em atividades (ABC) foi verificar o efetivo consumo de recursos da área administrativa pelas três principais linhas de mercadorias comercializadas (Medicamentos, Perfumarias e Hospitalar), com a finalidade precípua de determinar mais adequadamente a rentabilidade de tais segmentos de mercado. A necessidade dessa informação surgiu pela suposição de que a estrutura física necessária e os recursos operacionais despendidos mensalmente eram muito discrepantes, em termos de valor, de uma linha de comercialização para outra.

Para situar o leitor acerca da complexidade operacional mencionada, convém salientar que, para cada linha de mercadorias, a empresa disponibiliza funcionários, equipamentos (computadores, móveis etc), área física e material de consumo. Porém, a empresa realiza a venda das mercadorias de várias formas:

a) através do setor de Telemarketing (com cerca de 90 funcionários exclusivamente utilizados nesse setor);

b) por intermédio da Internet (em home page específica);

c) pela negociação direta com alguns grandes clientes (sem intervenção do Telemarketing);

d) atuando como "Operador Logístico" para três laboratórios (somente com produtos da linha de medicamentos) e

e) participando de licitações para venda a órgãos públicos (principalmente na linha hospitalar).

Além disso, para apoiar as operações dos três grupos de mercadorias mencionados, são utilizados recursos de diversos setores administrativos, como "Desenvolvimento de softwares", "Centro de Processamento de Dados -CPD", "Microinformática", "Tesouraria", "Contabilidade", "Pessoal/RH", "Crédito e Cobrança" e "Diretoria de Negócios".

Mesmo com as características citadas, para determinar a rentabilidade final das linhas de mercadorias a alocação dos gastos do Centro Administrativo era efetuada com base no seu percentual em relação às vendas totais do mês em análise, ou seja, se num determinado período as despesas contabilizadas nos diversos setores do Centro Administrativo representassem $4,5 \%$ do faturamento total, esse mesmo percentual era atribuído às três linhas igualitariamente. Ainda agravava o quadro mencionado o fato de que, pelas peculiaridades do segmento de atuação, as margens de contribuição obtidas com boa parte das mercadorias vendidas eram menores que $5 \%$. Com isso, a atribuição das despesas do Centro Administrativo poderia representar um fator decisivo na rentabilidade final das linhas de mercadorias referenciadas, acarretando distorções na mensuração do desempenho das mesmas.

Para minimizar as dificuldades relativas à determinação da efetiva rentabilidade de cada linha de comercialização, cogitou-se a respeito da utilização do $A B C$. Assim, no que tange à implementação do $A B C$ na empresa em tela, foram transpostas as seguintes etapas:

1) divisão da organização em processos operacionais;

2) mapeamento das atividades executadas nos processos enfocados;

3) alocação dos recursos (salários, encargos sociais, depreciação de equipamentos, aluguel do prédio, energia elétrica) às atividades encontradas;

4) análise das informações obtidas.

As etapas mencionadas são descritas nas próximas seções.

\subsection{Divisão da Empresa em Processos Operacionais}

Após análise detida do funcionamento da organização em lume, dividiu-se a empresa em três processos: (1) compra, (2) armazenagem e (3) venda. Os processos de compra e venda são desenvolvidos no Centro Administrativo (CA) da empresa, enquanto o processo de armazenagem acontece no Centro de Distribuição (CD).

O processo "compra" abrange todas as atividades relacionadas com a aquisição de mercadorias como a negociação com fornecedores quanto a preços, prazos e condições de entrega, o pagamento de duplicatas e respectiva baixa, o processamento de informações sobre pedidos pendentes e a posição dos saldos de estoques, dentre outras.

Quanto ao processo "venda", é pertinente descrevê-lo como a parte das operações em que são executadas atividades que contribuem para as vendas da empresa, cuja abrangência se estende pelas negociações com clientes, elaboração de promoções, análise de crédito, recebimento de pedidos (por telemarketing, Internet ou fax), processamento de pedidos, cobrança de contas a receber e poste- 
rior baixa dos recebimentos e, ainda, o apoio aos clientes (pós-venda).

O processo de "armazenagem" compreende todas as atividades desenvolvidas no Centro de Distribuição $(C D)$, abrangendo desde a recepção física das mercadorias até o momento em que são despachadas para os clientes.

Mesmo que o ABC, também, tenha sido implementado no processo de armazenagem, em virtude da exigüidade de espaço, priorizou-se relatar apenas os processos de compra e venda, cujos principais aspectos da fase de mapeamento de atividades são abordados na seção a seguir.

\subsection{Mapeamento das Atividades dos Processos de Compra e Venda}

$\mathrm{Na}$ segunda etapa da aplicação do $\mathrm{ABC}$, foi necessário acompanhar o dia-a-dia dos diversos departamentos envolvidos nos processos de compra e venda, visando identificar as atividades relacionadas a eles.

Através das entrevistas realizadas com os funcionários dos vários setores do Centro Administrativo, além das atividades vinculadas diretamente aos processos de compra e venda, foram encontradas algumas atividades que eram executadas no Centro Administrativo (CA), mas que tinham ligação de forma apenas "indireta" com tais processos. Ainda, alguns gastos foram considerados "estruturais", ou seja, não atribuíveis aos dois processos em tela em razão de existirem independentemente ou pela impossibilidade de encontrar um direcionador adequado.

Por isso, os encarregados do projeto de implementação decidiram segregar as atividades identificadas no Centro Administrativo em "atividades diretas", "atividades indiretas" e "gastos estruturais". Em termos de "gastos estruturais" foram classificados nessa categoria os dispêndios de recursos provenientes dos Centros de Custos: "Diretoria", "Segurança", "Recepção", "Conservação", "Almoxarifado" e "Telefonia".

Por outro lado, foram consideradas como "atividades indiretas" aos processos enfocados as atividades desenvolvidas nos seguintes setores:

1) Desenvolvimento: setor da empresa em que são desenvolvidos ou aprimorados softwares de controles internos.

2) CPD (Centro de Processamento de Dados): onde são processadas as rotinas de informática que suportam todas as operações da empresa.

3) Microinformática: setor responsável pela manutenção de mais de uma centena de computadores e periféricos associados que são utilizados no cotidiano gerencial da organização.

4) Tesouraria: setor da empresa responsável pelos procedimentos dos pagamentos e movimentação bancária da empresa.

5) Contabilidade: onde são executadas as atividades ligadas à contabilização, ao levantamento das demonstrações contábeis e demais tarefas afins.

6) Pessoal/RH: responde pelo recrutamento, seleção e treinamento dos funcionários da organização.

Quanto ao rol de atividades classificadas como "diretas", foram identificadas ao longo dos processos de compra e venda aproximadamente 60 (sessenta) atividades, conforme enfocado a seguir.

\subsubsection{Atividades Ligadas ao Processo de Compra das Três Linhas de Mercadorias}

Conforme mencionado anteriormente, a empresa mantém estrutura administrativa específica para as linhas de "Medicamentos", "Perfumarias" e "Hospitalar". Com isso, após entrevista com os responsáveis pelos setores que atuam na aquisição de mercadorias das três linhas, foram mapeadas as principais atividades requeridas para cada linha de comercialização, elencadas no quadro 1.

\begin{tabular}{|c|c|}
\hline \multicolumn{2}{|r|}{ Setor: Compras-Medicamentos } \\
\hline Código & Descrição \\
\hline ADCMed.-1 & Elaborar e emitir pedido de compra \\
\hline ADCMed.-2 & Cadastrar produtos novos \\
\hline ADCMed.-3 & $\begin{array}{l}\text { Informar fornecedores (demanda e nível de } \\
\text { estoque) }\end{array}$ \\
\hline ADCMed.-4 & $\begin{array}{l}\text { Negociar com fornecedores (pessoalmente } \\
\text { ou por telefone) }\end{array}$ \\
\hline ADCMed.-5 & $\begin{array}{l}\text { Outras atividades do setor compras-medi- } \\
\text { camentos }\end{array}$ \\
\hline ADCMed.-6 & Contabilizar compras e contas a pagar \\
\hline ADCMed.-7 & Pagar e baixar contas a pagar \\
\hline
\end{tabular}

Continua 
Conclusão

\begin{tabular}{|c|c|}
\hline Código & $\begin{array}{l}\text { Setor: Compras-Perfumarias } \\
\text { Descrição }\end{array}$ \\
\hline ADCPerf.-1 & Elaborar e emitir pedido de compra \\
\hline ADCPerf.-2 & Cadastrar produtos novos \\
\hline ADCPerf.-3 & $\begin{array}{l}\text { Negociar com fornecedores (pessoalmente } \\
\text { ou por telefone) }\end{array}$ \\
\hline ADCPerf.-4 & $\begin{array}{l}\text { Outras atividades do setor compras- } \\
\text { perfumarias }\end{array}$ \\
\hline ADCPerf.-5 & Contabilizar compras e contas a pagar \\
\hline \multirow[t]{2}{*}{ ADCPerf.-6 } & Pagar e baixar contas a pagar \\
\hline & Setor: Compras-Hospitalar \\
\hline Código & Descrição \\
\hline ADCHosp.-1 & Elaborar e emitir pedido de compra \\
\hline ADCHosp.-2 & Cadastrar produtos novos \\
\hline ADCHosp.-3 & $\begin{array}{l}\text { Negociar com fornecedores (pessoalmente } \\
\text { ou por telefone) }\end{array}$ \\
\hline ADCHosp.-4 & Outras atividades do setor compras-hospitalar \\
\hline ADCHosp.-5 & Contabilizar compras e contas a pagar \\
\hline ADCHosp.-6 & Pagar e baixar contas a pagar \\
\hline
\end{tabular}

Fonte: Elaborado pelo autor com base nos controles internos da empresa.

\section{Quadro 1 - Lista de atividades do processo de compra}

Em seguida foram enumeradas as atividades ligadas ao processo de venda, detalhadas no próximo tópico.

\subsubsection{Atividades Associadas ao Processo de Venda das Linhas de Mercadorias}

Para concretizar suas vendas a empresa mantém um conjunto de cinco setores exclusivamente voltados para tal finalidade: "Negócios" (que coordena os demais), "Crédito e Cobrança", "VendasMedicamentos", "Vendas-Perfumarias" e "VendasHospitalar".

De início, foram determinadas as atividades relacionadas a cada um dos referidos setores, como evidenciado no quadro 2.

\begin{tabular}{|c|c|}
\hline & Setor: Negócios \\
\hline Código & Descrição \\
\hline ADN-1 & Assessorar clientes e representantes \\
\hline ADN-2 & Assessorar crédito e cobrança \\
\hline ADN-3 & Negociar campanhas e promoções \\
\hline ADN-4 & Elaborar tablóides promocionais \\
\hline ADN-5 & Conferir relação de faturamento de clientes \\
\hline ADN-6 & Negociar devolução de mercadorias \\
\hline ADN-7 & Informes diversos à diretoria \\
\hline ADN-8 & Televendas (exceções) do setor \\
\hline ADN-9 & Outras atividades \\
\hline & Setor: Crédito e Cobrança \\
\hline Código & Descrição \\
\hline ADCC-1 & Analisar e liberar pedidos de clientes \\
\hline ADCC-2 & $\begin{array}{l}\text { Controlar depósitos em conta-corrente } \\
\text { efetuados por clientes }\end{array}$ \\
\hline ADCC-3 & Prorrogar duplicatas de clientes \\
\hline ADCC-4 & Controlar cheques recebidos de clientes \\
\hline ADCC-5 & Cadastro de clientes novos \\
\hline ADCC-6 & Acompanhamento da inadimplência \\
\hline ADCC-7 & Controle de cheques devolvidos de clientes \\
\hline ADCC-8 & Controle de créditos a clientes \\
\hline & Setor: Vendas-Medicamentos \\
\hline Código & Descrição \\
\hline ADVMed.-1 & Promoções semanais (panfletos) \\
\hline ADVMed.-2 & Receber pedidos por telemarketing \\
\hline ADVMed.-3 & Receber e processar pedidos pela Internet \\
\hline ADVMed.-4 & $\begin{array}{l}\text { Receber e processar pedidos do Operador } \\
\text { Logístico "A" }\end{array}$ \\
\hline ADVMed.-5 & $\begin{array}{l}\text { Receber e processar pedidos do Operador } \\
\text { Logístico "B" }\end{array}$ \\
\hline ADVMed.-6 & $\begin{array}{l}\text { Receber e processar pedidos do Operador } \\
\text { Logístico "C" }\end{array}$ \\
\hline ADVMed.-7 & Processar pedidos do telemarketing no CPD \\
\hline ADVMed.-8 & Analisar e liberar crédito \\
\hline ADVMed.-9 & Cobrar e baixar contas a receber \\
\hline ADVMed.-10 & Contabilizar vendas e contas a receber \\
\hline
\end{tabular}

Continua 
Conclusão

\begin{tabular}{|c|c|}
\hline & Setor: Vendas-Perfumarias \\
\hline Código & Descrição \\
\hline ADVPerf.-1 & Promoções semanais (panfleto) \\
\hline ADVPerf.-2 & Elaborar revista de ofertas \\
\hline ADVPerf.-3 & Receber pedidos pelo telemarketing \\
\hline ADVPerf.-4 & Receber e processar pedidos da Internet \\
\hline ADVPerf.-5 & Processar pedidos do telemarketing no CPD \\
\hline ADVPerf.-6 & Analisar e liberar crédito \\
\hline ADVPerf.-7 & Cobrar e baixar contas a receber \\
\hline ADVPerf.-8 & Contabilizar vendas e contas a receber \\
\hline & Setor: Vendas-Hospitalar \\
\hline Código & Descrição \\
\hline ADVHosp.-1 & Prospectar novos clientes \\
\hline ADVHosp.-2 & Negociação com clientes \\
\hline ADVHosp.-3 & Cotações e licitações \\
\hline ADVHosp.-4 & Processar pedidos no CPD \\
\hline ADVHosp.-5 & Analisar e liberar crédito \\
\hline ADVHosp.-6 & Cobrar e baixar contas a receber \\
\hline ADVHosp.-7 & Contabilizar vendas e contas a receber \\
\hline ADVHosp.-8 & Receber e processar pedidos do telemarketing \\
\hline
\end{tabular}

Fonte: Elaborado pelo autor com base nos controles internos da empresa.

\section{Quadro 2 - Lista de atividades do processo de venda}

A próxima seção comenta acerca do direcionamento dos recursos às atividades executadas para comprar e vender as três linhas de comercialização enfocadas.

\subsection{Alocação dos Recursos às Atividades de cada Linha de Mercadorias}

Depois de definida a lista de atividades que compõem os processos de compra e de venda, passou-se à etapa de atribuição de valores para cada atividade. Para determinar o valor mensalmente consumido em cada atividade executada, após exame da Contabilidade da empresa considerou-se que os recursos mais significativos relacionam-se com salários e encargos sociais dos funcionários atuantes nos dois processos, depreciação dos equi- pamentos utilizados, aluguel do prédio do Centro Administrativo, energia elétrica e telefone, conforme consta da tabela 1 a seguir.

\section{Tabela 1 - Recursos consumidos no período no Centro Administrativo}

\begin{tabular}{lcc} 
RECURSOS & VALOR (R\$) & $\%$ DO TOTAL \\
\hline Salários e encargos sociais & $169.132,23$ & $53,56 \%$ \\
\hline Telefone (inclusive telemarketing) & $131.865,11$ & $41,76 \%$ \\
\hline Depreciação de equipamentos & $5.967,23$ & $1,89 \%$ \\
\hline Aluguel do prédio & $5.118,32$ & $1,62 \%$ \\
\hline Energia Elétrica (fatura mensal) & $3.685,06$ & $1,17 \%$ \\
\hline TOTAL & $315.767,95$ & $100,00 \%$ \\
\hline
\end{tabular}

Fonte: Elaborado pelo autor com base nos controles internos da empresa.

Cabe destacar que os valores consignados, na tabela 1, dizem respeito aos gastos mensais de todos setores ou Centros de Custos sediados no Centro Administrativo, independentemente de serem relacionados (direta ou indiretamente) ou não, aos processos de compra e venda ora enfocados. Portanto, apenas parte daquele montante foi direcionada às atividades identificadas aos referidos processos. O valor restante foi considerado como "gasto estrutural", não sendo alocado aos processos mercantis em tela.

Pela metodologia do Custeio Baseado em Atividades $(A B C)$ os recursos são alocados às atividades com uso de direcionadores específicos para cada situação. Assim, no caso do "aluguel do prédio", o valor total pago mensalmente foi alocado às diversas atividades dos processos em questão com base na metragem quadrada da área física ocupada pelos setores onde eram realizadas as atividades. Em seguida, eram direcionadas às atividades com critérios específicos para cada caso. É pertinente ressaltar, também, que, como parte da área total é ocupada pelos setores considerados como "gastos estruturais", o valor respectivo acabou não sendo alocado às atividades para não distorcer o resultado final, posteriormente.

Quanto aos "salários e encargos sociais", para cada atividade foi possível identificar quais funcionários as executavam. Assim, bastou computar o valor desses fatores para os respectivos empregados utilizados nas atividades encontradas. Entretanto, houve casos em que alguns funcionários dividiam seu tempo em duas ou mais atividades. Para essas situações, optou-se por estimar o percentual de 
tempo gasto com cada atividade e, com base nessa proporção, dividiu-se o valor respectivo entre elas. Ainda, como no caso dos funcionários da Tesouraria, alguns funcionários de determinados setores poderiam destinar apenas parte de seu tempo às atividades relacionadas com os processos de compra e de venda. Com isso, parte desses recursos, também, foi desconsiderada em termos de alocação às atividades dos dois processos em lume.

No que tange à "depreciação dos equipamentos", os valores alocados às atividades foram obtidos junto ao controle de ativos permanentes da organização. Quando do levantamento das atividades, listaram-se os equipamentos empregados nelas. Assim, bastou computar os valores consignados pela Contabilidade e associá-los às diversas atividades.

Para os gastos relacionados com "energia elétrica", o seu direcionamento às atividades foi realizado com base no consumo estimado de energia em quilowatts/hora ( $k W h$ ) por mês, em cada atividade. Assim, todos os equipamentos (como impressoras, computadores, faxes, dentre outros) movidos à energia elétrica e utilizados nas atividades, bem como os pontos de iluminação respectivos, foram medidos em termos de consumo por hora de funcionamento. Em seguida, multiplicou-se esse valor pelo número de horas de uso mensal, obtendo-se uma estimativa do total consumido mensalmente para cada atividade. Com isso, se o consumo total mensal de quilowatts estimado para uma determinada atividade fosse de 3,5\% do montante previsto, do valor da fatura mensal de energia elétrica lhe seria atribuído o mesmo percentual.

Quanto ao valor mensal da conta de "telefone", incluía, além das ligações dos diversos setores administrativos, a parte utilizada para receber pedidos pelo setor de Telemarketing. A área de Telemarketing presta serviços para todas as linhas de mercadorias, mas em menor grau à linha Hospitalar, cuja fatia principal das vendas é realizada diretamente pelo setor incumbido para tal. A alocação aos setores e posteriormente às atividades se deu com base na listagem de ramais e o consumo mensal respectivo. Nos casos em que o mesmo funcionário executava mais de uma atividade, para distribuir o valor alocado ao ramal desse colaborador às atividades foi estimado um percentual com base nas entrevistas realizadas.

Adicionalmente, convém ressaltar que as "atividades indiretas", mencionadas na seção 3.2, também consumiram parte dos recursos citados na tabela 1. Por isso, quando cabível, parte dos valores atribuídos foram direcionados às atividades dos processos de compra e venda. Por exemplo: no caso do setor "Tesouraria", parte do seu tempo era consumida com os pagamentos a fornecedores e respectivas baixas. Com isso, apurou-se quanto caberia, em termos de valor, à atividade "Pagar e baixar contas a pagar" e subdividiu-se o montante entre as três linhas de mercadorias com base numa estimativa do número de pagamentos realizados para cada linha no período, respectivamente. Procedimentos semelhantes foram adotados para os demais setores agrupados sob a rubrica "Atividades indiretas" citados anteriormente, observadas as características que lhes são inerentes.

A tabela 2 expressa os valores direcionados às atividades do processo de compra.

\section{Tabela 2 - Valores direcionados às atividades do} processo de compra

\begin{tabular}{ll}
\hline \multicolumn{2}{c}{ Setor: Compras-Medicamentos } \\
Atividades & Valor (R\$) \\
\hline $\begin{array}{l}\text { ADCMed.-1 - Elaborar } \\
\text { e emitir pedido de compra }\end{array}$ & $6.637,15$ \\
\hline ADCMed.-2 - Cadastrar produtos novos & $1.233,13$ \\
\hline ADCMed.-3 - Informar fornecedores & \\
(demanda e nível de estoque) & $2.792,68$ \\
\hline
\end{tabular}

ADCMed.-4 - Negociar com fornecedores

(pessoalmente ou por telefone)

$12.222,50$

ADCMed.-5 - Outras atividades

do setor compras-medicamentos

$2.847,08$

ADCMed.-6 - Contabilizar

compras e contas a pagar

28,21

ADCMed.-7 - Pagar e baixar contas a pagar

$2.382,35$

TOTAL

$28.143,10$

Setor: Compras-Perfumarias

Atividades

Valor (R\$)

ADCPerf.-1 - Elaborar

e emitir pedido de compra

$4.137,89$

ADCPerf.-2 - Cadastrar produtos novos

$1.034,47$

ADCPerf.-3 - Negociar com fornecedores

(pessoalmente ou por telefone)

$11.379,20$

ADCPerf.-4 - Outras atividades

do setor compras-perfumarias

$2.586,18$

ADCPerf.-5 - Contabilizar

compras e contas a pagar

17,98

ADCPerf.-6 - Pagar e baixar contas a pagar

$1.518,51$

TOTAL

$20.674,24$ 
Conclusão

\begin{tabular}{lr}
\multicolumn{1}{c}{ Setor: Compras-Hospitalar } \\
Atividades & Valor (R\$) \\
ADCHosp.1 - Elaborar & 647,33 \\
\hline e emitir pedido de compra & 325,63 \\
\hline \multicolumn{2}{l}{ ADCHosp.2 - Cadastrar produtos novos } \\
\hline $\begin{array}{l}\text { ADCHosp.3 - Negociar com fornecedores } \\
\text { (pessoalmente ou por telefone) }\end{array}$ \\
\hline $\begin{array}{l}\text { ADCHosp.4 - Contabilizar } \\
\text { compras e contas a pagar }\end{array}$ \\
\hline \begin{tabular}{l} 
ADCHosp.5- Pagar e baixar contas a pagar \\
\hline
\end{tabular} & $1.290,75$ \\
\hline TOTAL & $1.426,43$ \\
\hline
\end{tabular}

Fonte: Elaborado pelo autor com base nos controles internos da empresa.

A tabela 3 apresenta as atividades do setor "Negócios" e do setor "Crédito e Cobrança" com os respectivos valores que lhes são direcionados.

Os valores totais das atividades dos setores mencionados na tabela 3 foram, posteriormente, redirecionados para o processo de venda, alocados às diversas linhas de mercadorias através de critérios próprios. Em razão de tais procedimentos, além das atividades do processo de venda citadas no quadro 2 , outras atividades foram acrescentadas ao rol das três linhas de mercadorias.

Ou seja, no caso do valor total alocado às atividades do setor "Crédito e Cobrança", esse foi distribuído às três linhas de mercadorias com base no percentual do número de análises e liberações de crédito que, em média, eram realizadas para as referidas linhas. Por esse critério, do valor de $R \$$ $17.353,17$, cerca de $42,80 \%$ foi direcionado à linha de Medicamentos (R\$7.427,81), 47,90\% à linha "Perfumaria" (R\$ 8.311,75) e 9,30\% à linha Hospitalar $(\mathrm{R} \$ 1.613,60)$.

No que respeita ao valor total direcionado às atividades do setor "Negócios", inicialmente as nove atividades foram divididas em três grupos:

a) GADN-1: Atividades de Venda/Negociação: envolvendo as atividades "Assessorar clientes e representantes", "Negociar devolução de mercadorias" e "Televendas (exceções) do setor", cujo total representa $\mathrm{R} \$ 9.652,59$;

b) GADN-2: Atividades de Propaganda: englobando as atividades "Negociar campanhas e promoções" e "Elaborar tablóides promocionais", totalizando $\mathrm{R} \$ 2.708,32$;
Tabela 3 - Valores direcionados às atividades dos setores "Negócios" e "Crédito e Cobrança"

\begin{tabular}{lr}
\multicolumn{1}{c}{ Setor: Negócios } & Valor (R\$) \\
Atividades & $6.237,40$ \\
\hline ADN-1 - Assessorar clientes e representantes & 338,54 \\
\hline ADN-2 - Assessorar crédito e cobrança & 338,54 \\
\hline ADN-3 - Negociar campanhas e promoções & $2.369,78$ \\
\hline ADN-4 - Elaborar tablóides promocionais & 135,42 \\
\hline ADN-5 - Conferir relação & $1.855,20$ \\
\hline de faturamento de clientes & 338,54 \\
\hline ADN-6 - Negociar devolução de mercadorias & $1.559,99$ \\
\hline ADN-7 - Informes diversos à diretoria & 365,62 \\
\hline ADN-8 - Televendas (exceções) do setor & $13.539,03$
\end{tabular}

\begin{tabular}{lc}
\multicolumn{1}{c}{ Setor: Crédito e Cobrança } & Valor (R\$) \\
Atividades & $6.310,06$ \\
\hline ADCC-1 - Analisar e liberar pedidos de clientes & \\
\hline $\begin{array}{l}\text { ADCC-2 - Controlar depósitos em } \\
\text { conta-corrente efetuados por clientes }\end{array}$ & $2.956,77$ \\
\hline ADCC-3 - Prorrogar duplicatas de clientes & 579,76 \\
\hline ADCC-4 - Controlar & 723,39 \\
\hline cheques recebidos de clientes & $1.971,18$ \\
\hline ADCC-5 - Cadastro de clientes novos & $2.319,04$ \\
\hline ADCC-6 - Acompanhamento da inadimplência & $1.391,42$ \\
\hline ADCC-7 - Controle de & $1.101,54$ \\
\hline cheques devolvidos de clientes & $17.353,17$ \\
\hline ADCC-8 - Controle de créditos a clientes
\end{tabular}

Fonte: Elaborado pelo autor com base nos controles internos da empresa.

c) GADN-3: Atividades burocráticas/outras: abrangendo as atividades "Conferir relação de faturamento de clientes", "Informes diversos à diretoria" e "Outras atividades do setor", que juntas somaram $\mathrm{R} \$ 839,58$.

Na seqüência, o montante de cada grupo de atividades do setor de Negociação foi direcionado às linhas de mercadorias. Para tanto, por entrevistas com os responsáveis pelo setor apurou-se uma estimativa de tempo destinado para cada uma das 
três linhas comercializadas. Mesmo não sendo um critério imune a contestações, para as peculiaridades da empresa em estudo foi a forma mais consistente encontrada para tal finalidade. Com isso, os valores dos três grupos mencionados foram subdivididos entre as três linhas de mercadorias, conforme consta da tabela 4.

\section{Tabela 4 - Valores atribuídos às atividades inerentes ao processo de venda}

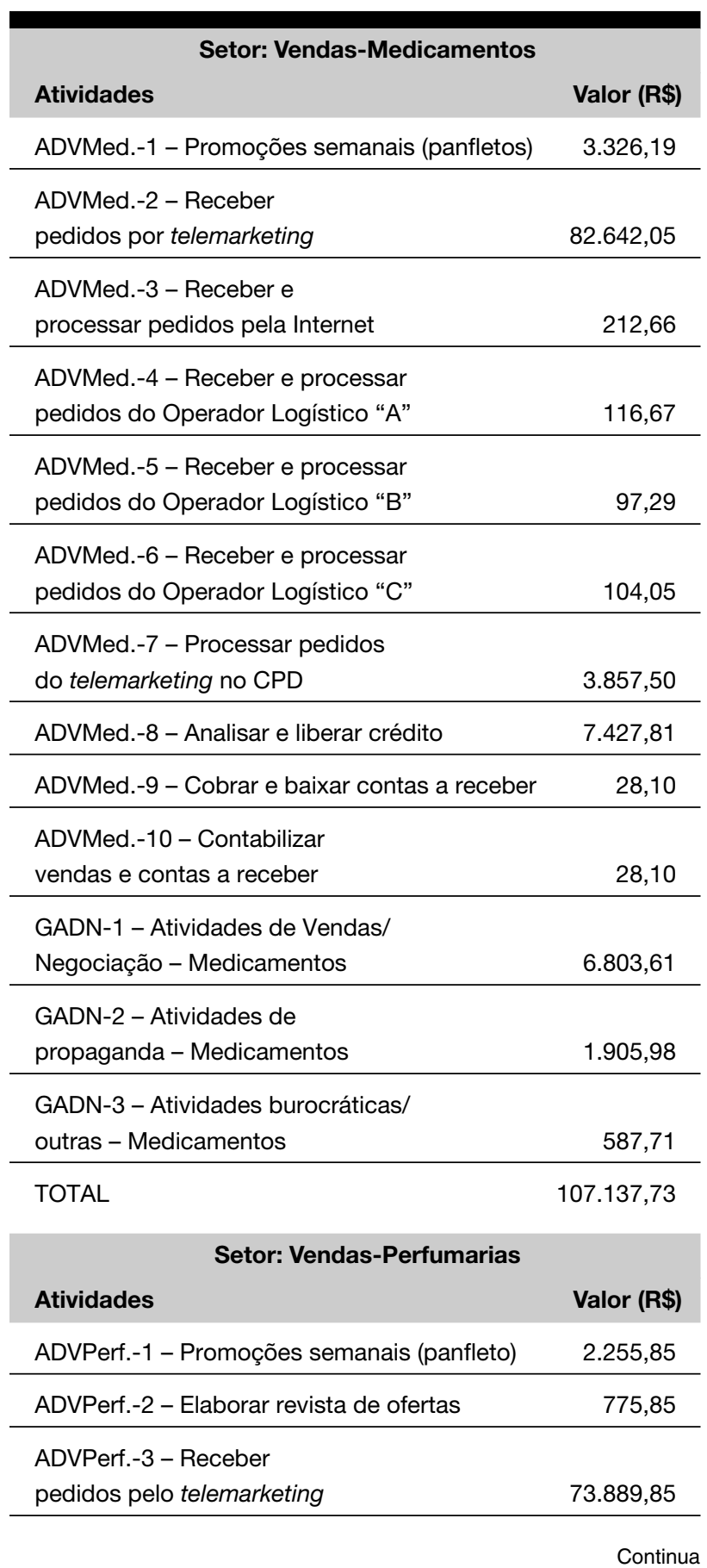

Conclusão

\section{Setor: Vendas-Perfumarias}

Atividades

Valor (R\$)

ADVPerf.-4 - Receber e

processar pedidos da Internet

4,46

ADVPerf.-5 - Processar pedidos

do telemarketing no CPD

ADVPerf.-6 - Analisar e liberar crédito

$8.311,75$

ADVPerf.-7 - Cobrar e baixar contas a recebe

23,42

ADVPerf.-8 - Contabilizar

vendas e contas a receber

GADN-1 - Atividades de

Vendas/Negociação - Perfumaria

$2.444,35$

GADN-2 - Atividades

de propaganda - Perfumaria

GADN-3 - Atividades

burocráticas/outras - Perfumaria

TOTAL

\begin{tabular}{lr}
\multicolumn{1}{c}{ Setor: Vendas-Hospitalar } & Valor (R\$) \\
Atividades & 600,26 \\
\hline ADVHosp.-1 - Prospectar novos clientes & $13.790,18$ \\
\hline ADVHosp.-2 - Negociação com clientes & $10.808,52$ \\
\hline ADVHosp.-3 - Cotações e licitações & $1.668,37$ \\
\hline ADVHosp.-4 - Processar pedidos no CPD & $11,513,60$ \\
\hline ADVHosp.-5 - Analisar e liberar crédito & 11,56 \\
\hline ADVHosp.-6 - Cobrar e baixar contas a receber & \\
\hline ADVHosp.-7 - Contabilizar & 795,26 \\
\hline vendas e contas a receber & \\
\hline ADVHosp.-8 - Receber e & \\
processar pedidos do telemarketing & 404,63 \\
\hline GADN-1 - Atividades de \\
Vendas/Negociação - Hospitalar & $29.864,39$ \\
\hline GADN-2 - Atividades & 118,49 \\
\hline de propaganda - Hospitalar & \\
\hline $\begin{array}{l}\text { GADN-3 - Atividades } \\
\text { burocráticas/outras - Hospitalar }\end{array}$ & \\
\hline TOTAL & \\
\hline
\end{tabular}

Fonte: Elaborado pelo autor com base nos controles internos da empresa.

Conhecido o valor gasto mensalmente para executar as atividades desenvolvidas nos dois processos mercantis em questão, passou-se a analisar as informações oriundas do uso do $A B C$ na empresa em tela. 


\subsection{Análise das Informações Obtidas Através do ABC}

A implementação do ABC, conforme evidenciado nas seções anteriores, facultou a obtenção de diversas informações de cunho gerencial. Nas próximas seções são evidenciadas, pela limitação de espaço, apenas as mais significativas em termos dos objetivos da empresa ao empregar o custeio baseado em atividades.

\subsubsection{Consumo de Recursos pelas Linhas de Mercadorias}

Uma das informações relevantes propiciadas pelo $A B C$ foi o efetivo consumo de recursos pelas três linhas de mercadorias comercializadas, no que se refere aos itens costumeiramente considerados como despesas. Com isso, permitiu-se a avaliação de rentabilidade das linhas de forma mais confiável em relação ao procedimento anteriormente utilizado.
Ou seja, antes de utilizar o $A B C$ a empresa determinava o percentual das despesas do Centro Administrativo em relação à Receita Operacional Líquida $(\mathrm{ROL})$ e o repassava às três linhas para fins de apurar o resultado após a margem de contribuição total proporcionada por tais segmentos de mercado.

Com a finalidade de ilustrar tal procedimento, reproduz-se a demonstração de resultado de um determinado período das três linhas em estudo na tabela 5. No mês em destaque, o percentual das despesas do Centro Administrativo em relação à Receita Operacional Líquida $(\mathrm{ROL})$ foi de $1,68 \%$, sendo que tal percentual foi utilizado para distribuir o valor total dessas despesas às linhas de mercadorias.

Após o custeamento baseado em atividades, o resultado final das linhas de mercadorias enfocadas foi alterado. Conforme consta da tabela 6 , foi possível direcionar os gastos do Centro Administrativo (relacionados aos processos de Compra e Venda) às linhas, implicando numa melhor alocação de tais recursos.

Tabela 5 - Demonstração de resultado sem o ABC (com valores sem os centavos e arredondados)

\begin{tabular}{lcccccccc} 
& \multicolumn{2}{c}{ MEDICAMENTOS } & \multicolumn{2}{c}{ PERFUMARIA } & \multicolumn{2}{c}{ HOSPITALAR } & \multicolumn{2}{c}{ TOTAL } \\
FATORES & Valor (R\$) & $\%$ & Valor (R\$) & $\%$ & Valor (R\$) & $\%$ & Valor (R\$) & $\%$ \\
Receita Oper. Líquida & 9.699 .311 & $100,0 \%$ & 6.040 .963 & $100,0 \%$ & 3.020 .482 & $100,0 \%$ & 18.760 .756 & $100,0 \%$ \\
\hline Custos e desp. variáveis & $(9.234 .211)$ & $-95,2 \%$ & $(5.425 .390)$ & $-89,81 \%$ & $(2.733 .214)$ & $-90,49 \%$ & $(17.392 .814)$ & $-92,71 \%$ \\
\hline Margem de contribuição & 465.110 & $4,8 \%$ & 615.574 & $10,19 \%$ & 287.268 & $9,51 \%$ & 1.367 .942 & $7,29 \%$ \\
\hline Despesas do C. Adm. & $(163.252)$ & $\mathbf{- 1 , 6 8 \%}$ & $(101.677)$ & $\mathbf{- 1 , 6 8 \%}$ & $(50.839)$ & $\mathbf{- 1 , 6 8 \%}$ & $(315.768)$ & $\mathbf{- 1 , 6 8 \%}$ \\
\hline Resultado do período & 301.848 & $3,11 \%$ & 513.897 & $8,51 \%$ & 236.429 & $7,83 \%$ & 1.052 .174 & $5,61 \%$ \\
\hline
\end{tabular}

Fonte: Elaborado pelo autor com base nos controles internos da empresa.

Tabela 6 - Demonstração de resultado após a aplicação do ABC (com os valores sem os centavos e arredondados)

\begin{tabular}{|c|c|c|c|c|c|c|c|c|}
\hline \multirow[b]{2}{*}{ FATORES } & \multicolumn{2}{|c|}{ MEDICAMENTOS } & \multicolumn{2}{|c|}{ PERFUMARIA } & \multicolumn{2}{|c|}{ HOSPITALAR } & \multicolumn{2}{|c|}{ TOTAL DO PERÍODO } \\
\hline & Valor (R\$) & $\%$ & Valor (R\$) & $\%$ & Valor (R\$) & $\%$ & Valor (R\$) & $\%$ \\
\hline Receita Oper. Líquida & 9.699 .311 & $100,0 \%$ & 6.040 .963 & $100,0 \%$ & 3.020 .482 & $100,0 \%$ & 18.760 .756 & $100,0 \%$ \\
\hline Custos e desp. variáveis & $(9.234 .211)$ & $-95,2 \%$ & $(5.425 .390)$ & $-89,81 \%$ & $(2.733 .214)$ & $-90,49 \%$ & $(17.392 .814)$ & $-92,71 \%$ \\
\hline Margem de contribuição & 465.110 & $4,8 \%$ & 615.574 & $10,19 \%$ & 287.268 & $9,51 \%$ & 1.367 .942 & $7,29 \%$ \\
\hline \multicolumn{9}{|l|}{ Despesas do C. Adm. } \\
\hline Processo de Compra & $(28.143)$ & $-0,29 \%$ & $(20.674)$ & $-0,34 \%$ & $(3.707)$ & $-0,12 \%$ & $(52.524)$ & $-0,28 \%$ \\
\hline Processo de Venda & $(107.138)$ & $-1,10 \%$ & $(92.072)$ & $-1,52 \%$ & $(29.864)$ & $-0,99 \%$ & $(229.074)$ & $-1,22 \%$ \\
\hline Resultado após ABC & 329.819 & $3,40 \%$ & 502.828 & $8,32 \%$ & 253.696 & $8,40 \%$ & 1.086 .344 & $5,79 \%$ \\
\hline \multicolumn{7}{|c|}{ Gastos Estruturais (não direcionados às linhas de mercadorias) } & $(34.170)$ & $0,18 \%$ \\
\hline Resultado do período & & & & & & & 1.052 .174 & $5,61 \%$ \\
\hline
\end{tabular}

Fonte: Elaborado pelo autor com base nos controles internos da empresa. 
Como pode ser percebido na tabela 6 , parcela dos gastos do Centro Administrativo ( $\mathrm{R} \$ 34.170)$ não foi direcionada às linhas de mercadorias por ser considerada como gastos estruturais pelos motivos aventados anteriormente (seção 3.3).

Já a alocação dos recursos às atividades que compõem os processos de Compra e Venda implicou em resultados díspares em relação aos calculados pela metodologia anterior (tabela 5). A alteração nos valores ocorrida pode ser visualizada no gráfico 1 , que faz um comparativo entre o resultado das linhas "antes" e "após" a implementação do custeio baseado em atividades (ABC) na distribuidora de mercadorias em tela.

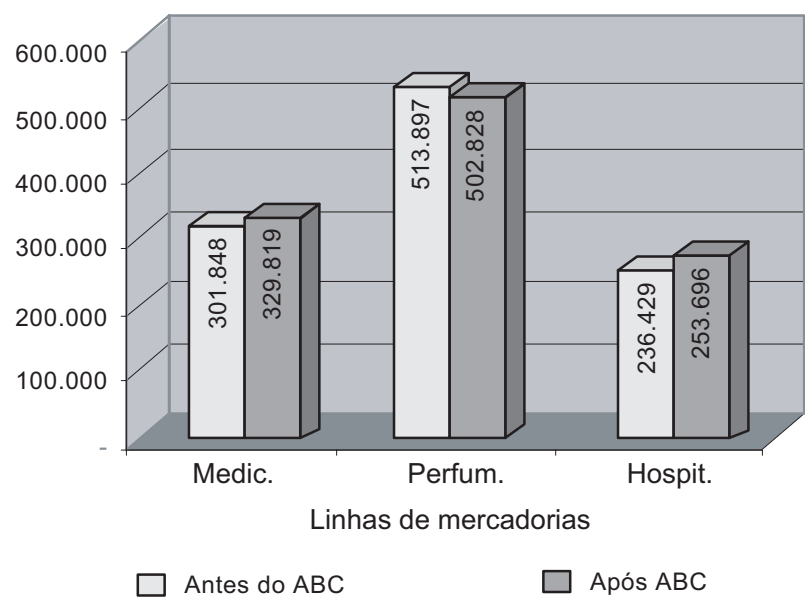

Fonte: Elaborado pelo autor com base nos controles internos da empresa.

\section{Gráfico 1 - Resultado final das linhas de mercadorias antes e após o ABC (em R\$)}

Constata-se que a mudança no procedimento de alocação dos recursos utilizados pelas três linhas de comercialização ocasionou, pelo ABC, um aumento nos resultados atribuídos às linhas de "Medicamentos" (+ R\$ 27.971) e "Hospitalar" (+ R\$ 17.267) e uma redução de $R \$ 11.069$ no que tange à linha "Perfumaria". Com isso, obteve-se resultados mais confiáveis, de vez que os valores oriundos das "Despesas do Centro Administrativo" foram alocados por critérios mais consistentes a cada uma das linhas enfocadas, enquanto que anteriormente eram atribuídos por percentual igual $(1,68 \%$, conforme tabela 5), independentemente do consumo efetivo de recursos em cada linha.

Outra forma de evidenciar a alteração ocorrida pela adoção do $A B C$ no desempenho das linhas examinadas é analisar o percentual do seu resultado em relação ao valor da Receita Operacional Líquida (ROL), como consta do gráfico 2 .

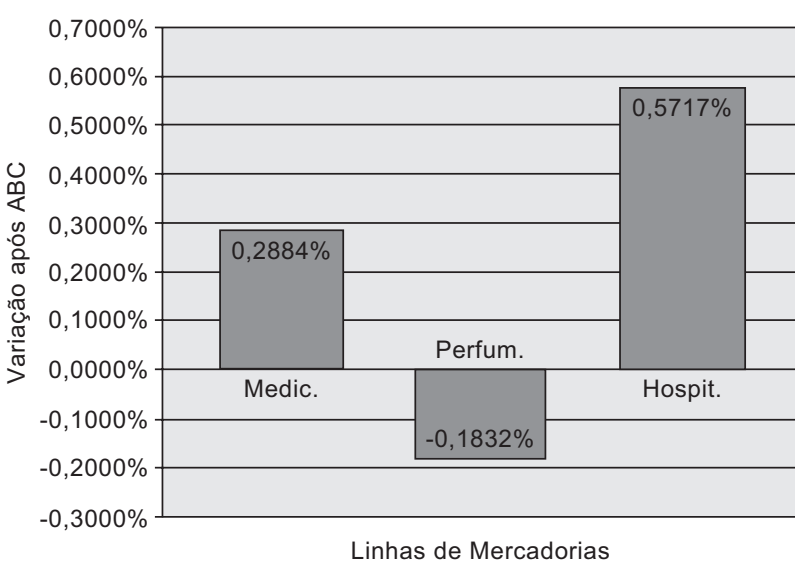

Fonte: Elaborado pelo autor com base nos controles internos da empresa.

\section{Gráfico 2 - Variação percentual no resultado final das linhas após aplicação do ABC}

O gráfico 2 evidencia que, enquanto o resultado final da linha "Perfumaria" decresceu 0,1832 pontos percentuais (equivalente a $R \$-11.069$ ), os resultados das linhas "Medicamentos" e "Hospitalar" aumentaram 0,2884 e 0,5717 pontos percentuais (o que representa $R \$+27.971$ e $R \$+17.267$ ), respectivamente, em comparação com a Receita Operacional Líquida (ROL).

A próxima seção evidencia a possibilidade de analisar as atividades sob a óptica de agregação de valor.

\subsubsection{Identificação de Atividades que não Agregam Valor}

Pela aplicação do ABC puderam ser identificadas algumas atividades que não agregam valor $e$ que podem ser objeto de iniciativas no sentido de minimizar o dispêndio de recursos de forma inadequada, como os exemplos citados a seguir.

No primeiro caso, junto com a nota fiscal de venda a distribuidora emitia um boleto para cobrança bancária da transação comercial realizada. Entretanto, alguns clientes atrasavam o pagamento e era permitido a quitação das duplicatas em atraso através de depósito em conta corrente. Tal permissão implicava na existência de quatro atividades distintas (Controle dos depósitos bancários de clientes, Controle dos cheques recebidos, Controle dos cheques devolvidos de clientes e Identificação dos depósitos em conta corrente) executadas em dois setores ("Crédito e Cobrança" e "Tesouraria"). Com essas atividades a empresa gastava cerca de $\mathrm{R} \$ 5.447,11$ por mês, ou seja, anualmente eram alocados recursos da ordem de $\mathrm{R} \$ 65.365,35(\mathrm{R} \$$ $5.447,11 \times 12$ meses) para algo que poderia ser eli- 
minado ou restringido com algumas medidas administrativas.

Numa outra situação, foram elencadas as atividades ligadas à devolução de mercadorias, como (i) negociar devoluções de mercadorias (executada no setor "Negócios"), (ii) controle de devolução das mercadorias aos fornecedores (efetuado pela "Tesouraria") e (iii) recepção e registro das devoluções (atividade executada no processo de armazenagem, não descrito neste artigo). A alocação de recursos a essas atividades, através do $A B C$, proporcionou constatar que a empresa gastava, aproximadamente, $\mathrm{R} \$ 5.801,97$ por mês. Ao multiplicar tal valor por 12 meses, verificou-se que a entidade despendia cerca de $R \$ 69.623,70$ por ano somente com a parte burocrática das devoluções (ou seja, sem considerar o valor das mercadorias devolvidas propriamente dito). Tal ponto mereceu ser devidamente avaliado pelos gestores e iniciativas para reduzir ou eliminar essa forma de desperdício puderam ser encetadas (como o controle da data de validade dos lotes de produtos, por exemplo, evitando o envio de mercadorias com prazo de validade próximo do encerramento).

Um outro conjunto de atividades que não agregam valor pôde ser associado à necessidade de atender aos fornecedores no sentido de informar-Ihes a respeito da demanda mensal e o nível de estocagem ao final de cada período, especificamente para a linha de Medicamentos. Para tanto, eram requeridas as atividades de (i) "Informar fornecedores-demanda e nível de estoque" (executada no setor "Compras-Medicamentos"), (ii) "Informar demanda para laboratórios" e (iii) "Suporte a VANS" (essas últimas realizadas pelo CPD). As três atividades, mensalmente, consumiam o valor de $R \$ 4.509,77$, conforme as estimativas realizadas pela metodologia $A B C$. Convertendo o valor mensal para gasto anual (multiplicando-se por 12 meses), verificava-se que representava algo em torno de $\mathrm{R} \$ 54.117,21$. É um valor significativo e poderia ser economizado (ou reduzido) com ações no sentido de disponibilizar o acesso dos próprios fornecedores à base de dados da distribuidora, por exemplo.

Nos três casos citados, que implicavam em gasto anual de $R \$ 189.106,26(R \$ 69.623,70+R \$$ $65.365,35$ + $R \$ 54.117,21$ ), percebeu-se a relevância de visualizar as diversas atividades executadas na empresa no sentido de minimizar os dispêndios ineficientes, que, em muitas ocasiões, não são sequer percebidos pelos administradores.

Porém, é conveniente ressaltar, também, que as referidas atividades não agregadoras de valor não puderam ser totalmente eliminadas de imediato, mas sua identificação permitiu que fossem convenientemente analisadas e que fossem estudadas formas para reduzi-las gradativamente.

\section{CONSIDERAÇÕES FINAIS}

O acirramento da concorrência entre as empresas tem sido notório nos últimos anos, forçando a redução das margens de lucro. Adicione-se a isso a constatação de que os gastos administrativos associados aos processos operacionais vêm aumentando em termos de percentual de participação nos dispêndios totais. Tais constatações verificadas no hodierno ambiente empresarial implicam na necessidade de avaliar com mais atenção o desempenho dos segmentos de mercado em termos da sua rentabilidade.

Para essa finalidade, uma das ferramentas que podem ser utilizadas é o Custeio Baseado em Atividades (ABC). Como demonstrado no estudo de caso descrito neste artigo, essa forma de custeio pode contribuir de forma significativa com a oferta de subsídios que proporcionem uma melhor gestão dos recursos das empresas, mesmo em empresas distribuidoras de mercadorias.

Nesse sentido, o direcionamento de recursos às linhas de mercadorias com base no $A B C$ proporcionou uma avaliação do desempenho de forma mais confiável em relação àquela anteriormente empregada na empresa estudada (conforme demonstrado na seção 3.4.1). Ainda, a identificação de atividades classificáveis como não agregadoras de valor (evidenciada na seção 3.4.2) facultou aos administradores a possibilidade de encetar ações visando à eliminação ou redução de gastos que não contribuem para maximizar a riqueza dos investidores.

A aplicação do $A B C$ na empresa pesquisada mostrou, ainda, que mesmo não abrangendo todos os dispêndios relativos ao Centro Administrativo (como os chamados "gastos estruturais" citados na tabela 6), a metodologia é perfeitamente aplicável a esse tipo de empresa, trazendo benefícios informativos que compensam os esforços realizados para implementação desse método de custeio. 


\section{REFERÊNCIAS BIBLIOGRÁFICAS}

ATKINSON, A. A.; BANKER, R. D.; KAPLAN, R. S.; YOUNG, S. M.. Contabilidade gerencial. São Paulo: Atlas, 2000.

BOISVERT, H.. Contabilidade por Atividades: contabilidade de gestão: práticas avançadas. São Paulo: Atlas, 1999.

BRIMSON, J. A.. Contabilidade por atividades: uma abordagem de custeio baseado em atividades. São Paulo: Atlas, 1996.

CATELLI, A.; GUERREIRO, R.. Uma crítica do sistema ABC - Activity Based Costing. São Paulo: IOB (Temática Contábil), n. 39, 1994.

COGAN, S.. Activity-based costing (ABC): a poderosa estratégia empresarial. 3. ed. São Paulo: Pioneira, 1994.

DE ROCCHI, C. A.. Sistema de custeamento de atividades (ABC costing) versus mapa de localização de custos: um estudo comparativo. Revista do Conselho Regional de Contabilidade do Rio Grande do Sul. Porto Alegre, v. 23, n. 77, abr./jun. 1994.

KAPLAN, R. S.; COOPER, R.. Custo \& Desempenho: administre seus custos para ser mais competitivo. $2^{\mathrm{a}}$. ed. São Paulo: Futura, 1998.

LEONE, G. S. G.. Curso de contabilidade de custos. 2. ed. São Paulo: Atlas, 2000.
MARTINS, E.. Contabilidade de Custos. 9. ed. São Paulo: Atlas, 2003.

NAKAGAWA, M.. ABC: custeio baseado em atividades. São Paulo: Atlas, 1995.

SAKURAI, M.. Gerenciamento integrado de custos. São Paulo: Atlas, 1997.

SANTOS, E. O.. Administração financeira da pequena e média empresa. São Paulo: Atlas, 2001.

SHANK, J. K.; GOVINDARAJAN, V.. A revolução dos custos: como reinventar e redefinir sua estratégia de custos para vencer em mercados crescentemente competitivos. 2a. ed. Rio de Janeiro: Campus, 1997.

WARREN, C. S.; REEVE, J. M.; FESS, P. E.. Contabilidade gerencial. São Paulo: Pioneira Thomson Learning, 2003.

YOUNG, S. D.; O’BYRNE, S. F.. EVA ${ }^{\circledR}$ e gestão baseada em valor: guia prático para implementação. Porto Alegre: Bookman, 2003.

NOTA:

Endereço do autor:

Universidade do Sul de Santa Catarina

Av. José Acácio Moreira, 787 - Dehon

Tubarão - SC

88704-900 